\title{
VARIATION IN THE DATE OF LEAF-OUT IN JACKSON HOLE'S DECIDUOUS HABITATS: EFFECTS OF A LATE SPRING ON BREEDING BIRDS
}

\author{
MARTIN L. CODY $\uparrow$ DEPARTMENT OF ECOLOGY \& EVOLUTIONARY BIOLOGY \\ UNIVERSITY OF CALIFORNIA LOS ANGELES
}

\begin{abstract}
$\downarrow \quad$ ABSTRACT
Deciduous trees and shrubs such as willows, cottonwoods and aspens, are common habitats in Jackson Hole, where their leaf-out dates, dependent on accumulated growing-degree-days (Gdd), vary year to year by well over a month. In 2010 these habitats had not yet leafed out by early June, and many trees and shrubs were not in full leaf until the middle of June. Leaf-out dates of temperate deciduous trees and shrubs are known to be determined by accumulated "degree-days" calculated as the number of degrees above some minimum (e.g. $5^{\circ} \mathrm{C}$ ) summed over time since the winter thaw. Some resident birds apparently track these variations and are able to occupy habitats at higher densities in early years. Migrants, with no prior knowledge of conditions in Jackson Hole, typically return to breeding habitats on schedules adapted to match the average leaf-out dates. In both early and late years their densities are lower, compared to densities in average years.
\end{abstract}

\section{$\uparrow \quad$ INTRODUCTION}

Three common and distinctive vegetation types in GTNP are deciduous - the low-lying willow flats, the hillside aspens and the riverside cottonwoods. All of these habitats are dominated by plants in the family Salicaceae, in two genera (Salix and Populus, sister taxa within the family) that are widespread across North America as well as Eurasia. They are also relatively similar in their bird species composition, and a number of birds, especially warblers and sparrows, are common breeders across the range of the deciduous habitats. Deciduousness conveys certain properties on vegetation that are distinct from the evergreen conifers, and the birds respond to these habitats to some extent similarly and synchronously.

All three of the habitats are associated with some type of disturbance, but from different quarters. Willow flats depend on a high water table, and are in a wider sense determined by topography to funnel run-on and slow drainage to impede run-off. Cottonwoods are also a water-related vegetation type in Jackson Hole, where they are essentially river- and creek-side woodlands maintained by the deposition of organics at times of periodic flooding. Rivers erode their banks, carve out sweeping bends that may ultimately become oxbows, and play ongoing roles in the modification of the riparian vegetation. Aspens are generally not associated with disturbances from water channel perturbations, as they are a feature of hillsides rather than the flats. However, two other major disturbance factors are probably critical to their maintenance, namely fire and landslides.

\section{$\downarrow \quad$ RESUlTS AND DISCUSSION}

\section{Leaf-out dates and their variations}

The progress of the seasons in deciduous vegetation is measured by the two end points of the growing season, budbreak or leaf-out in the spring and leaf-fall at the season's end. The timing or phenology of these events, especially the former, were important to birds using deciduous habitats for breeding purposes, critically affecting food supplies for insectivores as well as cover from potential predators. For plants, the critical weather variable 
regulating the arrival of spring is temperature; the cumulative total "degree-days" of mean daily temperatures above some baseline value has been shown to be an excellent indicator of bud-break or leaf-out in deciduous trees. Different species respond to cumulative degree-days at different rates, and there is a strong phylogenetic component to the responses. Trees and shrubs in the family Salicaceae, which includes our willows, aspens and cottonwoods, are known for leafing out early in the spring, a trait related to underlying physiological and anatomical characteristics of the family, namely narrow xylem (water-conducting) vessels and fewer of them per trunk volume, giving them what is called a "diffuseporous" wood anatomy (Lechovics 1990). A study of bud-break and leaf-out in Quebec by Maycock (1961) found that quaking aspen was the first deciduous tree to green up, followed closely by willows and then other Populus, with $90 \%$ of aspen leaves unfolding on average after 125 growing degree-days (GDD: the cumulative sum, over days, of the degrees of daily mean temperatures $>5^{\circ} \mathrm{C}$, or $\left.>41^{\circ} \mathrm{F}\right)$. At the other end of the scale, hickories, walnuts, beeches and oaks (which are also related to each other phylogenetically) required >300 GDD to reach the $90 \%$ leaf-out stage of development; in general, in any particular location, the suite of coexisting deciduous trees leaf out one after another, in a standard sequence.

As might be expected, leaf-out in the deciduous woodlands and shrub varies widely from year to year with spring temperatures. Figure 1 illustrates this variability over the last $20 \mathrm{y}$ in Jackson Hole (based on Moran weather data). In the upper part of the figure, the left-hand histogram shows the distribution of the first day of the year that contributes to GDD - in a way this could be considered the first day of spring. This date varies over a nearly 50 day interval (earliest: MAR $5^{\text {th }}$ in 2007; latest APR 22 $2^{\text {nd }}$ in 2006; mean date APR $6^{\text {th }}$ ). The right-hand histogram shows the distribution of the date by which 125 GDD have been accumulated in GTNP (mean date MAY $27^{\text {th }}$, earliest MAY $6^{\text {th }}$ in 1992, latest JUN 10 ${ }^{\text {th }}$ in 2010). Year 2010 was indeed a banner year, with leaf-out delayed a full five weeks past the earliest leaf-out dates in the last 20 years, and two weeks later than the average.

The lower part of the figure shows how growing degree-days are accumulated, on the average (large dots, with SD bars), and the actual time course to $90 \%$ leaf-out in an early year (1992), an average year (2000), and a late year (2010). It might be expected that this degree of variability in leaf-out dates amongst years would have an impact on the breeding birds of the deciduous habitats, with the potential to affect the onset and eventual success of a bird's reproductive season. There are potential consequences for the resident birds, which however are on hand to formulate a response to specific spring conditions as they become apparent. Migrant birds, though, will return to unpredictable conditions about which they presumably have no prior information.
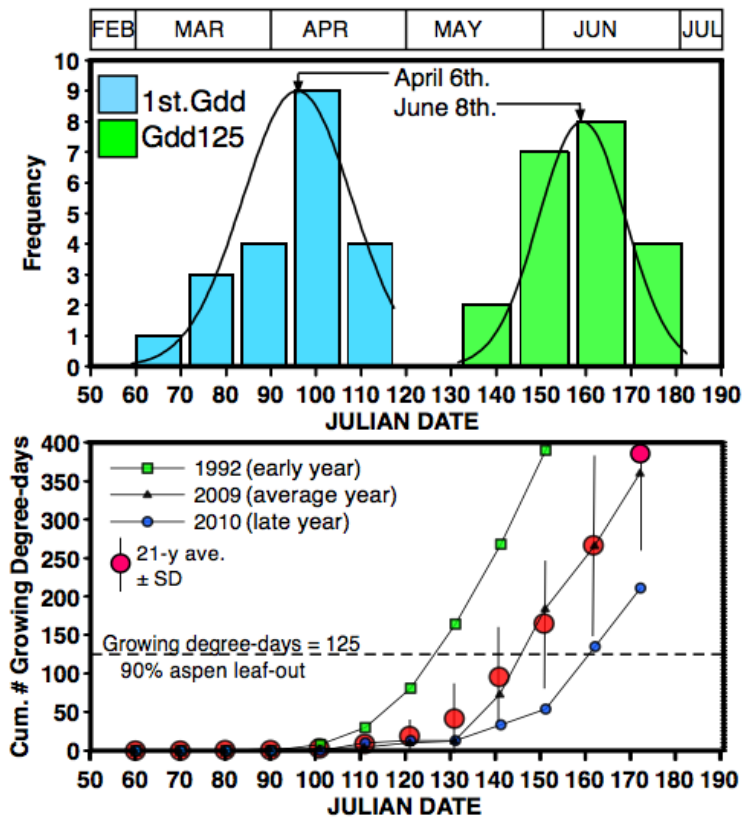

Figure 1.

\section{Migrants Returning to Breed in Winter-deciduous Habitats}

As north temperate habitats emerge from winter, thaw, leaf out and warm into springtime, they become reoccupied by the birds that left them behind some months previously. The general pattern is, not surprisingly, that short-distance migrants return earlier than the long-distance migrants. More critically, inter-year variation in the return timing of short-distance migrants is affected by the weather, such that in early or warm springs, i.e. years of early budbreak, they arrive back in breeding habitats sooner than in late or cool springs. Not so, however, with the long-distance migrants, whose return dates tend to be fixed with a limited variance around a constant mean, as a number of phenological data bases attest. They go by an absolute timetable rather than one related to the local weather. In Maine, the short-distance migrants American Robin, Song Sparrow and Fox Sparrow return generally in mid to late March; Yellow-bellied Sapsucker and Whitethroated Sparrow in the latter half of April; House Wren, Yellow Warbler, Least Flycatcher and 
Lincoln's Sparrow sequentially in the first half of May; and Warbling Vireo, Eastern Wood-pewee and Willow Flycatcher in that order in the latter half of May. These northeastern data are recorded (yearly, and even published in local newspapers!) at very close to the latitude of Jackson Hole, where all of the same species or very close congeneric relatives (Rednaped for Yellow-bellied Sapsucker, White-crowned for White-throated Sparrow, Western for Eastern Wood-pewee) occur. To the west but again at a similar latitude, records from Malheur National Wildlife Refuge in Oregon show the same ordered sequence of returning spring migrants (http://www.fws.gov/malheur/pdf/birdarrivaldates.pdf), and we can presume it holds for Jackson Hole also.

Migrants returning from southerly wintering grounds, where they have no knowledge of conditions in the distant northerly breeding grounds, are apparently adapted to arrive in breeding habitat to match an average year. Circumstantial evidence (given only inferential leaf-out dates derived from local weather data) from the GTNP birds supports this view. A comparison of inferred leaf-out dates and subsequent breeding densities is informative. Figure 2 shows that the two common, long-distance migrants of the cottonwoods (at long-term monitoring Sites \#15 and 16) that are foliage insectivores, Yellow Warbler and Warbling Vireo, both occupy this habitat at statistically significant higher densities in average years. The ordinate is density in pairs per hectare, standardized since two cottonwood sites (15 and 16) are combined in the plot. The abscissa in the Julian date by which 125 growing degree days (GDD) have been accumulated; the frequency distribution of this date (over the $20 \mathrm{y}$ during which the sites have been censused) is also shown. For a statistical test of the match between breeding density in any one year and spring budbreak, I compute regression equations with the former (breeding density) as dependent variable and the probability of the date of GDD125 for that year, read from the fitted normal distribution shown in the figure, as independent variable. The results are significant for all of the species depicted in the figure: densities are higher in normal years, lower in both early and late years. For the flycatchers in the cottonwoods, Empidonax species and Western Woodpewee, there is no relationship between breeding density and advent of spring, and the same is true for House Wren; this seems to indicate that the rewards of aerial flycatching (for flycatchers) and of trunk and branch gleaning (for the wren) are not critically dependent on the dates of foliage maturity.

Yellow Warblers reach higher densities in willows than in cottonwoods, but there is not a statistically significant relationship between their densities in these habitats (monitoring Sites 9-11) and budbreak timing. A possible explanation for this result would be that food resources are dependably high in the wetter willow habitats whether or not spring comes early or late-i.e. they are a good bet in any case. For the two commonest breeding sparrows in the willows, however, there is an influence on density by the timing of spring events. Both Song Sparrow, a short-distance migrant, and Lincoln's Sparrow, which winters much further south, are present in the willows at significantly higher densities in average years compared to early or late years (Figure 3, left-hand panel). In this figure I have assigned to the "average" category those years in which the Julian date of GDD125 is within one-half a standard deviation of the mean (i.e. JD 143-151), positioned between those with earlier or later dates

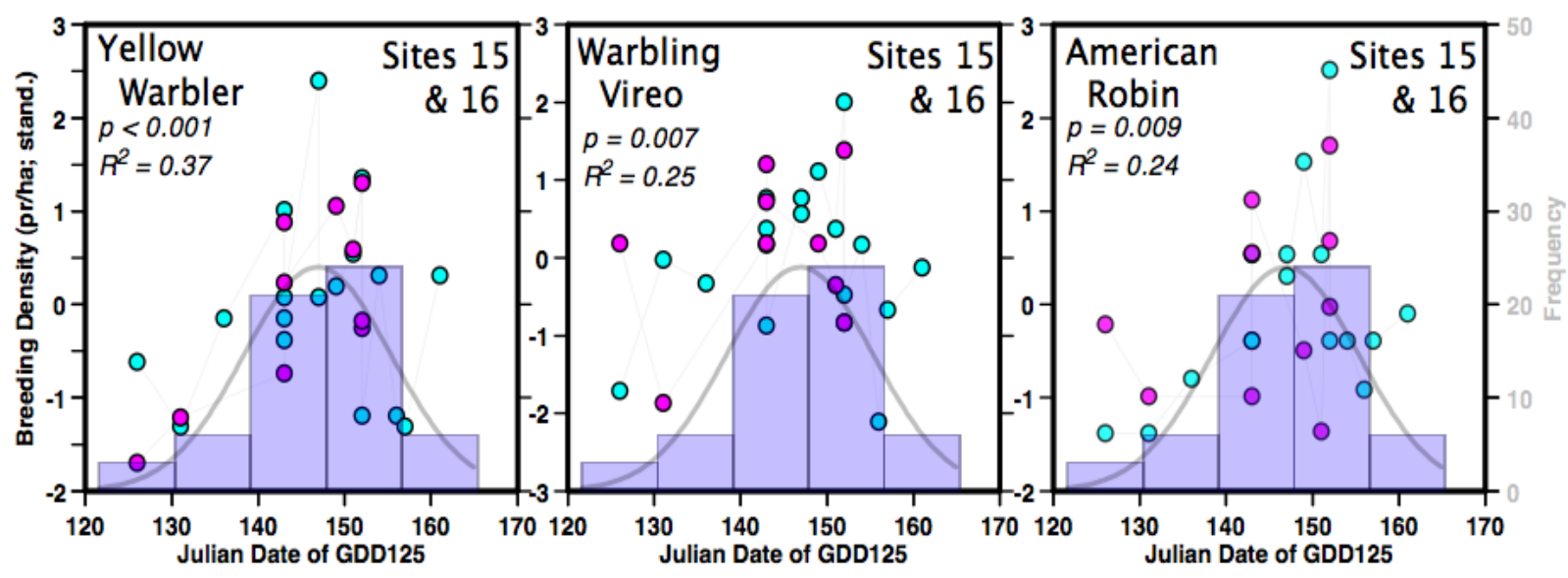

Figure 2. 

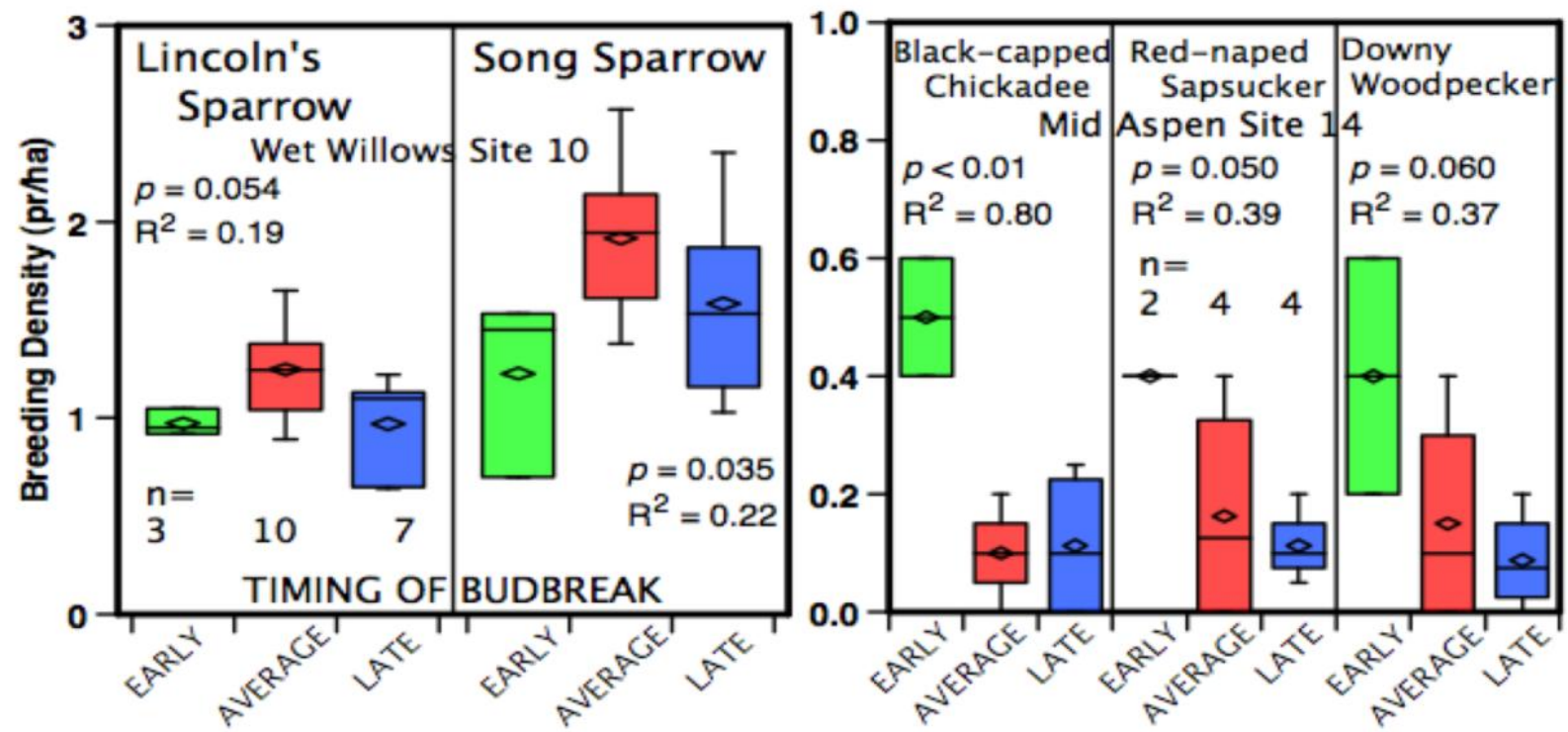

Figure 3.

(see Figure). For both species, which are very largely ground foragers, early or late springs at this site likely translate into wet or dry springs. I hypothesize that their similar responses to variation in GDD125 perhaps reflects their increased likelihood of occupying the willows when water levels there are neither very high (when foraging areas are extensively inundated) nor very low (when insect food supplies would attenuate earlier).

Three species most typical of the aspen woodlands are represented in Figure 3 (right-hand panel), the resident Black-capped Chickadee and Downy Woodpecker, and the migrant Red-naped Sapsucker. All are at or close to their highest GTNP breeding densities in aspens, for which monitoring Site 14, the Mid Aspen habitat, provides the most data. Of the 10 census years at this site, two were early, four were average and four late with respect to budbreak dates. All these species, which are trunk and branch feeders and not dependent on foliage or foliar insects, occur at higher breeding densities in early years, while not distinguishing between average and late years. Notably these are hole-nesting species with typically longer fledging times than open nesting species. They are absent or nearly so from willows, but all occur routinely in the cottonwoods. However, there are no significant relationships between breeding densities and spring budbreak dates in the cottonwood sites, although the trends, while lacking in statistical significance, are all toward higher densities in earlier years. As cottonwoods leaf out later than aspens, perhaps the advantage in an extended season is relatively greater in aspens, which are then proportionately more favored in the early budbreak years. There is clearly much still to be learned about habitat choice relative to spring budbreak, especially in the year-round residents, which would seem much better positioned, relative to the migrants, to monitor habitat phenologies and to capitalize on their year-to-year variations.

\section{$\uparrow \quad$ ACKNOWLEDGEMENTS}

Thanks once again to AMK director Prof. Hank Harlow for facilities, advice, and hospitality. This abbreviated account of effects of leaf-out variation on breeding birds has been redacted from my book "BIRDS IN SEASONAL ENVIRONMENTS: BREEDING BIRD POPULATIONS IN GRAND TETON NATIONAL PARK" which summarizes $20 \mathrm{y}$ of monitoring breeding bird densities in GTNP, and is currently in review.

\section{$\uparrow \quad$ Literature Cited}

Lechowics MJ. 1990. Why do temperate deciduous trees leaf out at different times? Adaptation and ecology of forest communities. Amer. Natur. 124:821-842.

Maycock PF. 1961. Botanical studies on Mont St. Hilaire, Rouville Co., Quebec. Canad. J. Bot. 39:1293-1325. 